\title{
Tabs and Tabulations:
}

\section{Results of a Transaction Log Analysis of a Tabbed-Search Interface}

\section{Authors}

Kelsey Brett, Resource Discovery Systems, University of Houston Libraries, Houston, Texas, USA

Elizabeth German Learning \& Outreach, Texas A\&M University Libraries, College Station, Texas, USA

Frederick Young, Resource Discovery Systems, University of Houston Libraries, Houston, Texas, USA

\section{Introduction}

Many choices must be made when a library implements a discovery system. One primary consideration is how to integrate the system into the library Web site. In 2011, the University of Houston Libraries launched a redesigned Web site that integrated the Serials Solutions discovery platform, Summon. One of the primary outcomes of the library Web site redesign was making search the most prominent feature on the homepage. The redesign included a tabbed-search interface where each tab corresponded to a different search tool: the online catalog (OPAC), an e-journal A-Z list, a research guide index, a database list, and Summon (see Figure 1). Summon became the default tab on the libraries tabbed-search interface and was branded "OneSearch." This article reports on user interactions with a tabbed-search interface through the analysis of a transaction log that recorded users' search activities within the tabbed interface.

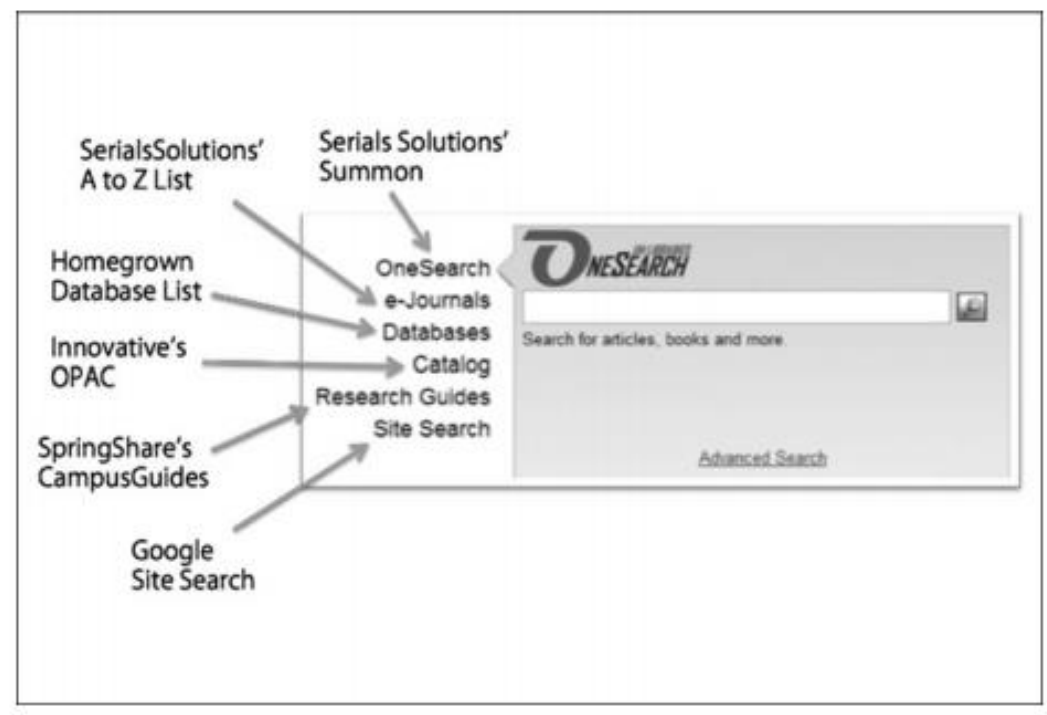

Figure 1 
A great deal of effort was put into redesigning the library Web site. The redesign of the Web site was the result of a yearlong investigation, carried out primarily by stakeholder engagement groups (SEGs) and an iterative design process. Four SEGs were established and charged with examining the Web site from the perspectives of design, collections and services, information architecture, and usability and assessment. The desired outcomes were a Web site with the following features:

- Is more usable, intuitive, and self-evident

- Is flexible and can be readily modified

- Facilitates use of our collections and services

- Minimizes the need for training

User surveys, usability testing, analysis of Web usage reports, as well as surveys of other library Web sites are examples of some of the methods used by each SEG. Each SEG produced a report with recommendations to guide and inform the Web site redesign. Subsequently, prototypes for the library homepage were created and then modified through an iterative process that resulted in a tabbed interface. Throughout the process, it was essential that the University of Houston Libraries maintained a user-centered focus. For this reason, a plan was developed to assess the Web site on a long-term basis, with a particular focus on the tabbed-search interface.

In order to observe how users interact with the tabbed-search interface as well as to assess how useful the tabs are for users, the University of Houston Libraries created a transaction log to unobtrusively collect anonymous user interactions with the tabbed-search interface (see Figure 2). The transaction log used on the University of Houston Libraries homepage is a Drupal module developed in-house by the libraries' Web Project Manager. When a user selects a tab and performs a search, a URL is generated. The URL contains data that populates fields in the transaction log. The transaction log data contains information about user searches and includes tab used; search terms; date, time, and location of search (on campus or off campus); and an ID to identify the user session. In addition to information about the search, each search session contains a unique ID to identify searches belonging to the same session. Data from this URL are parsed and written to a database. Next, a new URL is generated that sends the user to his or her intended interface and search results. The user is unaware of this process.

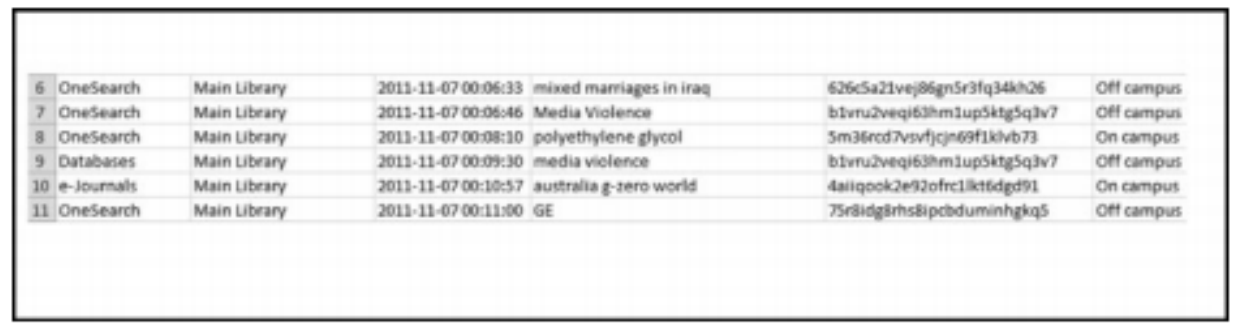

Figure 2

After several months of collecting data in the transaction log, a team was formed to code and analyze the data. The intention was that the findings would be used to apprise University of Houston Libraries' internal constituents about how users interact with the primary search interface, to inform future usability studies, and to support recommendations for improving the search interface. The following is a 
summary of the activities and findings of the team as well as their recommendations for improvement and the subsequent changes that were implemented as a result of the data analysis.

\section{Literature Review}

Library users are knowledgeable about services offered on the Web and have come to expect services that provide "user-centric, friendly, and reassuring" interactions (Sadeh 2008, 10). This reality challenges libraries to understand their users and how they search for information in order to provide a search experience that supports user needs and meets user expectations (TeagueRector and Ghaphery 2008). According to Suqing Liu, Sansan Liao, and Jing Guo (2009), library users want a single point of discovery and a speedy, easy-to-use interface when searching for library materials. However, a single point of discovery is not always ideal, as some users understand the need to search specific collections to meet their information needs (Teague-Rector, Ballard, and Pauley 2011).

Many academic libraries have selected Web-scale discovery systems to provide a Web-like search experience. Discovery systems are capable of quick information retrieval, provide simple interfaces, offer a single point of discovery, and are often promoted as providing the "Google-like" search experience that users have come to expect. Unfortunately, these platforms have not proven to be a catch-all solution for library searching. Discovery systems require the use of facets to narrow results; however, a usability study on Serials Solutions' Summon reported that users did not notice the facets until prompted (Ford 2010).

Additionally, many discovery systems are configured so that print holdings, electronic holdings, and in some cases, items outside the library's collections, are searchable simultaneously, which leads to the delivery of results that may not all be accessible online. Three different Summon usability studies reported that users were frustrated when presented with resources that were not available online (DeFelice 2009; Ford 2010; Howard and Weibrands 2011). Similarly, a usability study on Ex Libris's Primo revealed that users were disappointed at the lack of full-text options (Comeaux 2012). Furthermore, even when students are capable of using a discovery system to complete tasks, many still opt to use Google or Amazon.com due to lack of overall satisfaction with a discovery system (Djenno et al. 2014). Because discovery systems cannot satisfy every information need, many libraries choose to present their discovery tool as one of several options for searching library materials.

Providing access to a range of complex, searchable library collections is not an easy task. This explains, to some degree, why libraries have taken different approaches when presenting search options to users on their Web sites (Teague-Rector et al. 2011). Search has become the focal point of many academic library homepages. In 2008, Virginia Commonwealth University Libraries moved their left-aligned search box to the center of the page and reported a 51 percent increase in searches (Teague-Rector and Gaphery 2008). Providing a single search interface that searches across all library content reminds users of their other online interactions and builds confidence in the library's ability to meet their information needs from a single entry point.

The single search box can present challenges for some informationseeking tasks. For example, users may find that results do not meet their specific needs if search options are limited or do not provide access to specific collections (Lown, Sierra, and Boyer 2013). To meet the user's desire for a simplified search while also providing access to different collections of information, some libraries have designed their search results screen to present the top results from several systems. This design approach is commonly 
referred to as a "bento box," and it allows the user to choose a results set after conducting his or her search. After implementing the bento box model, North Carolina State University (NCSU) Libraries found that users frequently choose search results that are not articles or catalog items, highlighting the importance of making these items findable in a transparent and intuitive way (Lown et al. 2013).

On the other hand, a tabbed-search interface gives users the option to select a system before conducting a search. A 2011 study reported that students tend to select limiters prior to searching rather than post searching (Williams and Foster 2011). This practice was reinforced in a usability study conducted at James Madison University, which suggested that users are willing to deviate from the default search, particularly when asked to find a certain format (Fagan et al. 2012, 101). Usability testing suggests that users are quite good at choosing the correct tab for specific tasks. An NCSU usability test conducted by Susan Teague-Rector and colleagues $(2011,88)$ reported, "In well over half of the tasks completed, users selected a tab other than the default tab before beginning their search." Additionally, users tended to choose the correct tab to complete tasks involving books, journal titles, or library services, but had trouble choosing the correct tab for tasks involving journal articles and databases. Despite users' tendencies to choose a correct tab to complete tasks in usability testing, usage data, including that collected at University of Houston Libraries, suggest that the default tab is used at the highest rate.

The literature suggests that there is no "right" way to present search options to users. Continual assessment of user interactions with a search interface can help individual libraries determine whether they are on the right track. The method of assessment used in this study was a transaction log analysis. A transaction log unobtrusively collects information about users' interactions with a system, such as search queries entered into a Web search engine. Transaction log analyses can help to provide insight into user search behavior, inform systems design, and improve usability (Jansen 2006). Libraries have been using transaction logs for decades to gain insight into how users interact with their information retrieval systems; however, "a consistent methodology has not evolved, or been adopted, as the standard that can be replicated" (Asunka et al. 2008, 36-7), primarily because the problems and research questions that transaction logs are used to address vary among institutions (Asunka et al. 2008). In 2011, the National Digital Science Library of Korea analyzed one year's worth of search queries gathered through a transaction log to identify trends in user search behavior (Park and Lee 2013). Montana State University conducted an analysis of search queries collected by a transaction log in order to understand the types of searches users were conducting in their discovery system and rate the quality of those searches (Meadow and Meadow 2012). At University of Houston Libraries, a transaction log analysis was conducted for this study to gain understanding about how the tabbed-search interface was being used and whether each tab was being used appropriately.

\section{Methodology}

\section{Why Transaction Log Analysis?}

The transaction log analysis methodology was chosen for a number of reasons. First, it gives authentic user interactions with the system without researcher interference and allows for the user to operate within their own context, such as their office or dorm room. Second, it is a relatively low cost solution: No staff time is needed to go into recruitment for the study nor are any incentives necessary for participants. Third, an in-house transaction log allows some control over the data elements collected, which minimizes the amount of time invested in preparing the data for analysis. Last, transaction logs 
can gather a large amount of data from a wide variety of users. For example, this study recorded 2,509 different search sessions. Trying to capture that amount of data during in-person usability studies would be extremely costly and time consuming.

\section{Developing the Analysis Key}

In order to analyze the transaction log, the team must develop a key to code the data. The development of the key took place in multiple stages: (1) testing the transaction log and the key, (2) coding the data, and (3) analyzing the coded data. This multistage approach was taken not only to test the validity of the key and the validity of the transaction log but also to insure library buy-in for the results. In the first stage, an initial team made up of representatives from Web Services, Resource Discovery Systems, Electronic Resources, Instruction, and Access Services reviewed the data from the transaction log and developed a draft key for coding the data. While having a large group develop the initial key was not expedient, it was beneficial for two reasons: Having a range of individuals with different skill sets and backgrounds decreased the initial researcher bias going into the key development, and the wide range of individuals from multiple departments gave the necessary validity necessary to create buy-in across the library for the recommendations that the team would later propose.

Using the draft key, members of the initial team each coded the same 50 search queries. This process tested both the transaction log and the key developed to analyze the data. During this phase, the team identified an issue regarding repeated searches in the transaction log. Some queries were exactly the same and a few seconds to a minute apart in the transaction log. In some cases, these identical searches occurred in different tabs and appeared to be instances of "tab jumping." In the initial configuration of the log, there were no session ID variables to allow the team to track a user in a session, and an assumption must be made as to whether or not identical searches were evidence of tab jumping. The addition of a session identifier proved to be important in identifying search sessions and subsequently, trends in user searching that demonstrated users' confusion about which tab is appropriate for their particular search.

Additionally, the team found that some fields in the coding table, such as "tab inappropriate," required more rigid definitions. A review of the coded data revealed that the representatives from different departments had different understandings of when tab use was appropriate or inappropriate for a particular search. The team took a step back to define the types of searches that were appropriate for each tab. Once the library-wide representatives were satisfied with the coding key and the data elements collected in the transaction log, data collected over one week in November 2011 was selected for coding. A week in November was chosen when few library instruction sessions were scheduled. The research team was interested in unmediated interactions and wanted to avoid large amounts of data that were created in a classroom environment. The findings from that coding sample comprise the findings of this report.

A week of consecutive search queries was selected rather than a random sample of queries. The study attempted to look at a user's interaction with the search interface, and analyzing some user activities required looking at user searches for a session. As a user session can contain multiple queries, it is important to analyze consecutive search queries to identify trends in user searching. A random sampling of the data could potentially obscure identifiable trends. Although a random sample was not used, the data were considered sufficient because the number of queries analyzed was above the statistical 
number needed for a random sample. Additionally, the number of searches conducted in each tab in the sample set reflected similar ratios to the number of searches conducted in each tab overall.

\section{The Key in Detail}

The key used in this analysis was developed by a cross-departmental team within the library. Some of the data coded were not used in this study but could be used in the future. The data codes are described in Table 1.

- Date: If the search query included a date, such as a year or a day/month/year, the field was marked with an "X." This field was useful for identifying when a query included citation elements.

- Numbers: If the query contained a number, the researcher specified the type of number: ISBN, Call numbers, ISSN, OCLC, DOI, Standard, and Course numbers.

- Citation: This field was marked with an " $X$ " if the query included three or more elements of a citation.

- Author/Title combination: This field was created in response to the beta test. It was found that while full citation queries were common, even more common were queries that contained an author name and the title of a work.

- Title: If a query contained a title, the researcher specified if the title was a Journal, Article, Book, Conference Proceeding, Musical Work, Art Piece, $30 \mathrm{~K}$. Brett et al. Presentation, or Script. These were the most common titles identified in the beta test.

- Name: The researchers took a broad understanding of a "name." If a query contained a name, the query was coded with Person, Organization, Test, Geographic Location, or Database.

- Library information: If the query contained a search for library information such as hours, room reservations, or research guides, the research would mark this field with an "X."

- Tab jumping: If the user used the same search terms in multiple tabs within a session, with minimal modifications, this field was marked with an "X." The original search was not marked.

- Tab inappropriate: This field was marked with an " $X$ " if the search functionality of the tab was incapable of returning results for search terms. For example, searching a full citation in the eJournal tab would be inappropriate as the e-Journals tab is incapable of conducting a citation search. The team decided not to code any searches in the OneSearch tab as "Tab Inappropriate" because although it may not be the optimal tab for a particular search, it is capable of retrieving results for all types of searches categorized by our coding key. A small number of searches in the transaction log were complete outliers, such as Web URLs and e-mail addresses. Since those searches were very rare and would be considered inappropriate in any tab on search interface, they were not evaluated for any tab.

- Known/Unknown item search: Each query was marked as either Known Item (KI) or Unknown Item (UI). Queries were only marked as known item when the query indicated a clear intent on the user's part to locate a specific item. Queries were marked unknown item when the coder was unable to identify if the user intended to locate a specific item. That is not to say that all unknown item searches were topical searches; it is simply that based upon the search query, neither an information retrieval system nor a human could decipher if the user was attempting to find a specific item or was conducting a search on a topic. This was the most difficult field to code as there is room for ambiguity, and the researcher is required to make a judgment. For example, a search for "Nature" would be considered a known item if it was conducted in the e- 
Journals tab, but a search for "nature" would be considered an unknown item if searched within the Catalog tab.

\section{Table 1}

\begin{tabular}{|l|l|}
\hline Field & How to code \\
\hline Date & Mark with $\mathrm{x}$ \\
\hline Numbers & $\begin{array}{l}\text { Label with ISBN, Call \#, ISSN, OCLC, DOI, } \\
\text { Standard, Course \# }\end{array}$ \\
\hline Citation & Citation: Three or more elements, Mark with X \\
\hline Author/Title combination & Mark with $\mathrm{x}$ \\
\hline Title & $\begin{array}{l}\text { Label with Journal, Article, Book, Conference } \\
\text { Proceeding, Musical Work, Art Piece, } \\
\text { Presentation, Scripts }\end{array}$ \\
\hline Library information & $\begin{array}{l}\text { Label with Person, organization, Test, Geographic } \\
\text { Location, Database }\end{array}$ \\
\hline Tab jumping & $\begin{array}{l}\text { For things such as hours or a service or research } \\
\text { guide, Mark with } x\end{array}$ \\
\hline Tab inappropriate & $\begin{array}{l}\text { User moved from one tab to another with } \\
\text { minimal modifications, Mark with } x, \text { Do not mark } \\
\text { original search as tab jumping }\end{array}$ \\
\hline Known/Unknown item search & $\begin{array}{l}\text { Mark with } x \text { if search functionality is not capable } \\
\text { for search terms }\end{array}$ \\
\hline & $\begin{array}{l}\text { Label with KI, UI / Know items: When the query } \\
\text { indicates a clear intent on the user's part to } \\
\text { locate a specific item }\end{array}$ \\
\hline
\end{tabular}

\section{Coding Procedures}

Using the key above, the 4,300 search queries were divided among the researchers. Each researcher attempted to identify if the search query was a known item or an unknown item. This typically involved the individual replicating the user's query in the native interface of the tab the user chose and/or conducting a search within Google. The native interfaces for each system the tabs represent were used versus using the actual tabbed interface in order to avoid creating false entries into the transaction log. A Google search was conducted in order to avoid negative positives for a known item. For example, if a book existed, but the library did not own it, a search of the catalog would not return a result, but a search within Google clearly identified the user's query as a search for a known item.

\section{Finding and Analysis}

\section{Data Reliability and Tab Usage}

The first task was to test the reliability of the sample data. The tab usage from the sample data (one week of searches) was compared to a larger set of data (several months of searches). The ratio of tab use in the sample data was very similar to the ratio of tab use in the larger set of data, providing assurance that the sample set was reliable. The results showed that users search the default "OneSearch" tab most frequently, about 70 percent of the time, and neither the "Site Search" tab nor 
"Research Guides" tabs were used very often, about 1 percent and 2 percent of the time, respectively (see Table 2).

\section{Table 2}

\begin{tabular}{|l|l|l|l|l|}
\hline Tab & Total & \% of Total & \multicolumn{1}{l|}{ Sample } & \% of Sample \\
\hline OneSearch & 320,769 & 66.1 & 3,023 & 70.2 \\
\hline Catalog & 54,856 & 11.3 & 421 & 9.8 \\
\hline e-Journals & 52,529 & 10.8 & 431 & 10.0 \\
\hline Databases & 39,068 & 8.1 & 313 & 7.3 \\
\hline Research guides & 11,753 & 2.4 & 75 & 1.7 \\
\hline Site Search & 3,732 & 0.8 & 26 & 0.6 \\
\hline
\end{tabular}

\section{Tab Inappropriateness}

In order to find trends in inappropriate tab use, the log entries were coded as tab inappropriate if the search queries were performed in a tab incapable of returning the desired result. For example, searching for an article title in the "Catalog" tab is considered inappropriate because the catalog does not support this type of query. "OneSearch" and "Catalog" tabs have greater capabilities and broader intents than other tabs; for this reason, it was uncommon for them to be coded as "tab inappropriate." The "Ejournals" and "Databases" tabs, which have specific intents, were more likely to be used inappropriately when their purpose was not understood. The analysis revealed that the "e-Journals" and "Databases" tabs were used inappropriately at high rates: 29 percent of total searches in the "e-Journals" tab and 40 percent of total searches in the "Databases" tab were inappropriate. Twenty-nine percent of searches in the "Research Guides" tab and 46 percent of searches in "Site Search" tabs were inappropriate.

Although those tabs were also used inappropriately at high rates, their overall use was minimal, so it was difficult to identify trends (see Table 3 ).

Table 3

\begin{tabular}{|l|l|l|l|}
\hline Tab & \# inappropriate & Total \# of tab searches & \% inappropriate \\
\hline Catalog & 24 & 521 & 5.7 \\
\hline e-Journals & 123 & 431 & 28.5 \\
\hline Databases & 125 & 313 & 39.9 \\
\hline Research guides & 22 & 75 & 29.3 \\
\hline Site search & 12 & 26 & 46.1 \\
\hline
\end{tabular}

\section{Identifying User Tasks}

Common types of searches were extracted from the coded data to identify user tasks associated with each search. The most prominent distinction among types of searches is unknown item versus known item. Unknown item searching makes up 57 percent of the searches in the transaction log sample. Analysis of unknown-item searching is difficult because very little can be accurately inferred about the tasks associated with an unknown item search. Analysis of known-item searching gives some insight into the information-seeking behavior of users. Forty-three percent of the coded log entries indicate that users come to the library Web site looking for a specific item. The coded data was used to identify the most common tasks for known-item searching (see Table 4). 


\section{Table 4}

\begin{tabular}{|l|l|c|}
\hline \multicolumn{2}{|c|}{ Coded As: } & \multicolumn{2}{c|}{$\begin{array}{c}\text { Pssociated Task } \\
\text { Searches }\end{array}$} \\
\hline Unknown Items & User Tasks cannot be identified & 57 \\
\hline Known Items & I need to find a particular item & 43 \\
\hline Title: Book & I am looking for a book and I have the title & 11.7 \\
\hline Title: Article & I am looking for an article and I have the title & 10.2 \\
\hline Title: Journal & I am looking for a particular journal & 8.9 \\
\hline Name: Database & I am looking for a particular database & 4.3 \\
\hline $\begin{array}{l}\text { Marked Citation and Title: } \\
\text { Book }\end{array}$ & $\begin{array}{l}\text { I am looking for a book and I have some citation } \\
\text { information }\end{array}$ & 1.6 \\
\hline $\begin{array}{l}\text { Marked citations and Title: } \\
\text { Article }\end{array}$ & $\begin{array}{l}\text { I am looking for an article and I have some } \\
\text { citation information }\end{array}$ & 1 \\
\hline
\end{tabular}

\section{Tab Intent and Usefulness}

As mentioned above, in order to determine if a search was conducted in the appropriate tab, the team must define the intent and usefulness of each tab (see Table 5). The intent of a tab is the purpose for which it should be used (i.e., the intent of the "e-Journals" tab is to find a known e-journal). The usefulness of a tab is what the system behind the tab is capable of searching and returning (i.e., the "eJournals" tab is useful for searching for e-journal, e-book, and conference proceeding titles). The tab's intent and usefulness should be clearly conveyed to the user through the design of the search interface. If user behavior is inconsistent with either the intent or the usefulness of the tab, then the tab must be redesigned so that it more accurately reflects the types of searches that are appropriate within the tab.

\section{Table 5}

\begin{tabular}{|c|c|c|}
\hline Tab & Tab Intent & Tab Usefulness \\
\hline OneSearch & $\begin{array}{l}\text { Broad range of searches for } \\
\text { items that are owned, } \\
\text { licensed, or free; } \\
\text { Exploratory Searches; } \\
\text { Discovery of all types of } \\
\text { library materials }\end{array}$ & $\begin{array}{l}\text { For finding: known and unknown items; print items } \\
\text { owned by the library; electronic journals, articles, and } \\
\text { books; local archival and digital items } \\
\text { For searching by: Keyword Numbers; Titles; } \\
\text { Other Bibliographic Information; }\end{array}$ \\
\hline e-Journals & $\begin{array}{l}\text { To find a known full text } \\
\text { journal }\end{array}$ & $\begin{array}{l}\text { For finding: e-Journals, e-books, and conference } \\
\text { proceedings available through the library } \\
\text { For searching by: Partial or complete titles }\end{array}$ \\
\hline
\end{tabular}




\begin{tabular}{|l|l|l|}
\hline Databases & To find a database & $\begin{array}{l}\text { For finding: Databases available through by the library } \\
\text { For searching by: Keyword (limited to words contained } \\
\text { in the description); Titles }\end{array}$ \\
\hline Catalog & $\begin{array}{l}\text { Broad range of searches for } \\
\text { items owned by the library }\end{array}$ & $\begin{array}{l}\text { For finding: known and unknown items; print items } \\
\text { owned by the library, electronic journals and books, } \\
\text { and local archival and digital collections } \\
\text { For searching by: Keyword, Titles; Other bibliographic } \\
\text { information; numbers }\end{array}$ \\
\hline $\begin{array}{l}\text { Research } \\
\text { Guides }\end{array}$ & $\begin{array}{l}\text { To find a guide to resources } \\
\text { related to a subject or a } \\
\text { course }\end{array}$ & $\begin{array}{l}\text { For finding: known and unknown research guides } \\
\text { For searching by: keyword (limited to words contained } \\
\text { in the research guide pages); Title }\end{array}$ \\
\hline Site Search & $\begin{array}{l}\text { To find information about the } \\
\text { library, services, and events }\end{array}$ & $\begin{array}{l}\text { For finding: unknown information about the library } \\
\text { For searching by: keyword; numbers }\end{array}$ \\
\hline
\end{tabular}

Defining the intent and usefulness of each tab allowed the team to determine which tabs are appropriate for the identified user tasks. Calculations were made based on how often each task was attempted using each of the six tabs. The results presented a clear picture of how often users perform searches in appropriate tabs versus how often users perform searches in inappropriate tabs (see Table $6)$.

Table 6

\begin{tabular}{|l|c|c|c|c|c|c|}
\hline \multicolumn{1}{|c|}{ Tasks } & OneSearch & Catalog & $\begin{array}{c}\text { e- } \\
\text { Journals }\end{array}$ & Databases & $\begin{array}{c}\text { Research } \\
\text { Guides }\end{array}$ & $\begin{array}{c}\text { Site } \\
\text { Search }\end{array}$ \\
\hline $\begin{array}{l}\text { User task could not be } \\
\text { identified (unknown item) }\end{array}$ & 1865 & 207 & 153 & 157 & 34 & 20 \\
\hline $\begin{array}{l}\text { I need to find a particular } \\
\text { item (known item) }\end{array}$ & 1158 & 214 & 278 & 156 & 41 & 6 \\
\hline $\begin{array}{l}\text { I'm looking for an article and } \\
\text { I have some citation } \\
\text { information }\end{array}$ & 47 & 0 & 0 & 0 & 0 & 0 \\
\hline $\begin{array}{l}\text { I'm looking for an article and } \\
\text { I have the title }\end{array}$ & 412 & 3 & 14 & 10 & 2 & 0 \\
\hline $\begin{array}{l}\text { I'm looking for a book and I } \\
\text { have some citation } \\
\text { information }\end{array}$ & 60 & 8 & 0 & 0 & 0 & 0 \\
\hline $\begin{array}{l}\text { I'm looking for a book and I } \\
\text { have the title }\end{array}$ & 375 & 117 & 4 & 9 & 0 & 0 \\
\hline
\end{tabular}




\begin{tabular}{|l|c|c|c|c|c|c|}
\hline $\begin{array}{l}\text { I'm looking for a particular } \\
\text { database }\end{array}$ & 45 & 4 & 11 & 115 & 4 & 4 \\
\hline $\begin{array}{l}\text { I'm looking for a particular } \\
\text { Journal }\end{array}$ & 107 & 29 & 237 & 10 & 0 & 1 \\
\hline $\begin{array}{c}\text { Appropriatel Inappropriate I } \\
\text { Maybe }\end{array}$ & & & & & \\
\hline
\end{tabular}

Overall, the findings indicated that the tabbed-search interface successfully allows users to find what they are looking for, but they also indicated that some tabs required improvement. For example, 40 percent of searches in the "Databases" tab were inappropriate; contrary to its intent and usefulness, users attempted to conduct unknown-item searches in that tab. The analysis suggested that users who performed unknown-item searches did not understand that the "e-Journals" and "Databases" tabs were unlikely to return useful results. These tabs have very specific intents, and using them for unknown-item searching is likely to result in a frustrating and negative user experience.

Based on the analysis of the log, minor changes were recommended to better communicate to the user the intent and usefulness of each tab. The Web Services Department implemented the recommended changes as well as some heuristics recommendations to the look and feel of the tabbed-search interface. The e-Journals (see Figure 3) and databases tabs (see Figure 4) underwent the most dramatic changes because they were used inappropriately more frequently than the other tabs. To better communicate tab intent, the "e-Journals" tab was renamed to "e-Journal titles." Additionally, the text "search for online journals by title" was added to the search box, and a hint to use the "OneSearch" tab to find articles was added below the search box. The Web Services Department completely removed the search box from the database tab to encourage navigation to known databases via the alphanumeric index. $A$ browse by subject feature was also added to the "Databases" tab.

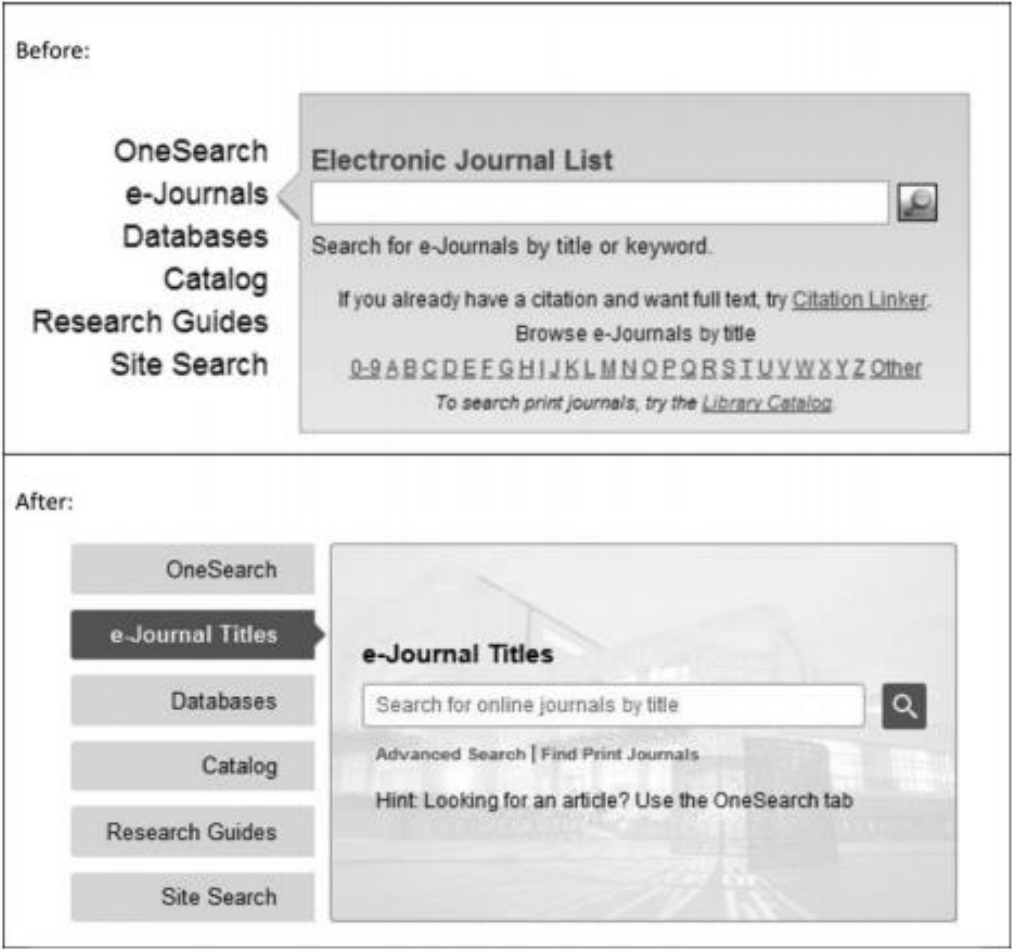

Figure 3 


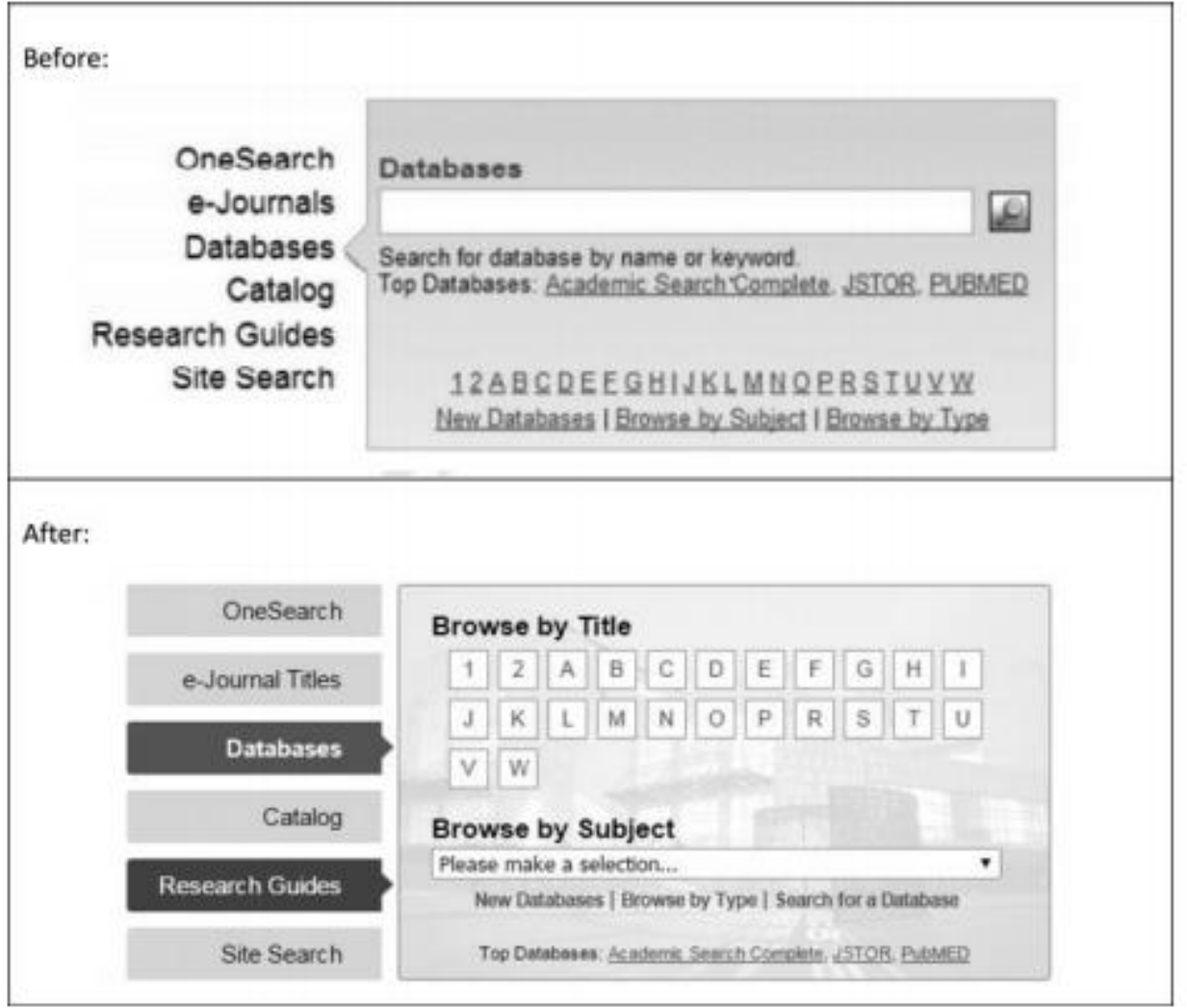

Figure 4

\section{The Transaction Log Revisited}

In 2014, the research team conducted a second analysis of the transaction log to assess the effects of the 2012 changes to the Web site's tabbed interface. For this analysis, the researchers coded a smaller set of data: 2,195 transaction log entries. This number is above the amount needed for a random sample, and like the previous sample set, this sample reflected similar percentages of searches in each tab. Also similar to the previous sample set, this sample was chosen from a week in November. After assessing the new coded data, it was clear that there have been successes with the modified tabs, but some areas still require improvement.

The most significant change was the removal of the search function from the database tab. This seems to have been a successful change. In the transaction log, we did not see users attempting database searches in other tabs to make up for the lost database search option. This was demonstrated by comparing the frequency of searches for databases by their name. In the first set of data, database searches by name accounted for 3.5 percent of all searches, but in the second set of data, database searches by name accounted for only 1.7 percent. Additionally, anecdotally there have not been any complaints from users nor from the library staff and librarians about the changes to the databases tab.

The e-Journal titles tab remains an issue that must be addressed. In the second sample, inappropriate use of the tab does not change despite the improvements to the tab interface: 30 percent of searches in the e-Journals title tab were considered inappropriate compared to 28.5 percent in the original analysis. Of the inappropriate searches in the "e-Journal Titles" tab in the second sample, 20 percent of queries 
were for known items such as a books or articles. Unknown items made up 80 percent of the inappropriate searches. Unknown item searching in the "e-Journals" tab is slightly higher in the original analysis, making up 84 percent of all inappropriate searches, but the second round of analysis suggests that the interface changes did not communicate to users that the intent of the "e-Journal Titles" tab does not include unknown item searching. The unknown item queries in the transaction log do not present a discernible trend: The queries ranged from extremely specific searches such as "auto expansion to china" to more broad searches such as "buffets." This range of queries could indicate that users are not necessarily attempting topical or subject searches. There are several speculative solutions to this problem that could include removing the e-Journal search feature as was done with the Database tab, adding title limiters to the tab as is done in the native interface, or accepting a 70-percent appropriate search rate as acceptable. Whatever solution is chosen, a periodic review of the transaction log will help to determine the success of the modification.

\section{Discussion}

"Ongoing evaluation of user search behavior using log data can uncover opportunities for improving search" (Lown et al. 2013, 240). The results of our analysis demonstrate that a transaction log is a valid method for providing insight into the usefulness of a tabbed-search interface. The transaction log analysis project at the University of Houston Libraries provided information about how users interact with the library's tabbed-search interface, where they encounter problems, and the types of information they seek.

A report of our findings was shared with other departments in the library and provided an opportunity to dialog with subject area specialists and public services staff about recommended improvements to the tabbed interface. The results were also used to develop a usability testing protocol, which was conducted prior to the implementation of the recommended changes.

\section{Transaction Log Insights and Future Research}

Issues with missing data and data preparation are common in transaction logs (Jansen 2006). By developing the transaction log in-house, we were able to avoid these issues for the most part. The tool developed to track user interaction with the tabbed-search interface outputs data in a format that does not require cleanup and needs little preparation before coding. Our test coding of the log data pointed out weaknesses in the original data elements included in the transaction log. Because we had some control over the development of the transaction log, these missing elements, such as session IDs and onor off-campus status, could be added. The resulting data included the elements required to begin our analysis. Though little preparation of the data was necessary, coding the data is time consuming. In the future, we may look for methods of automatically coding some portions of the transaction log to facilitate analysis.

Although our analysis of the transaction log was valuable in pointing out areas of improvement for the tabbed interface, such as removing the search box from the "Databases" tab and renaming the eJournals tab to "e-Journal Titles," it is not without its weaknesses. While the team could successfully determine whether a search was for a known or unknown item, and whether it was conducted in the appropriate tab, there was no certainty regarding why users were conducting a search in a particular tab, if they were satisfied with their search results, or if they found what they were looking for. Incorporating qualitative data (e.g., the results of usability tests or user interviews) with transaction log 
data would be a better method for capturing the overall effectiveness of the tabbed-search interface. Repeating the transaction log analysis in conjunction with usability studies of the search interface would better inform efforts to make user-centered, evidence-based decisions regarding our primary search interface.

\section{Search Tabs Insights and Future Research}

Although the default tab is used at a higher rate at the University of Houston Libraries, users also select other tabs for their searches. Users select the appropriate tab for specific tasks a majority of the time, which suggests that the tabbed interface model is adequate for meeting user needs. However, we do observe that search tabs with a broader intent (e.g., the Catalog tab) are used at a higher rate and are less likely to be used inappropriately. On the reverse side of the usage scale, search tabs with a specific intent (e.g., the e-Journal Titles tab) are used less frequently and are likely to be misused at a higher rate. This could point to a user's understanding that search tools with a broader intent are more likely to return useful results. This finding does indicate the need to pay attention to how the intent of these tabs is communicated to users, particularly in the case of tabs that have a specific use.

A closer examination of some of the search queries suggests that sometimes providing a simplified search interface in not enough. Though some improvements were made to the e-Journal titles tab, there was little to no change in inappropriate use. Though the transaction log analysis does not provide a clear reason for this behavior, a closer look at the queries for this tab reveal the possible need for more search options. Some queries included ISSN numbers, journal abbreviations, or partial journal title information. Although the search tool behind the e-Journal title tab supports these different types of searching, the search form for the e-Journal titles tab does not. Including additional search options would broaden the intent of the tab and potentially decrease inappropriate use of the tab.

The initial analysis of the transaction log indicated that searching the Databases tab is often ineffective. Here, a closer examination of the search queries led us to believe that users wanted to search within the databases, not necessarily for a particular database. There was some discussion among the study authors as to whether an "Articles" search tab would be more useful. Also of note is that the recommended changes to the Databases tab removed the option for searching; users are only presented with an alphanumeric index of links. Additional investigation must be given to developing a method for future evaluation of the database tab's use, perhaps through the use of click analytics.

\section{Conclusion}

Collecting and analyzing data about how users interact with the library's Web site lays a foundation for future user-centered developments and enhancements. Incorporating a transaction log into a tabbedsearch interface provides an avenue for libraries to perform ongoing evaluation of user search behavior. Analysis of this behavior offers some insights into how Web sites are being used (and in some cases misused) by users. This analysis project and the Web site changes that were made as a result of the findings are an example of how libraries can employ user-focused decision-making to inform Web site design. 


\section{References}

Asunka, Stephen, Hui Soo Chae, Brian Hughes, and Gary Natriello. 2008. "Understanding Academic Information Seeking Habits through Analysis of Web Server Log Files: The Case of the Teachers College Library Web Site." The Journal of Academic Librarianship 35 (1):33-45.

Comeaux, David J. 2012. "Usability Testing of a Web-Scale Discovery System at an Academic Library." College and Undergraduate Libraries 19 (2-4):189-206. http://dx.doi.org/10.1080/10691316.2012.695671.

DeFelice, Barbara. 2009. "An Evaluation of Serials Solutions Summon as a Discovery Service for Dartmouth College Library: Report Submitted to the Dean of Libraries and Librarian of College." Accessed December 12, 2013. www.dartmouth.edu/ library/admin/docs/Summon_Report.pdf.

Djenno, Mireille, Glenda Insua, Gwen M. Gregory, and John S. Brantly. 2014. "Discovering Usability: Comparing Two Discovery Systems at One Academic Library." Journal of Web Librarianship 8 (3):263-85.

Fagan, Jody Condit, Meris Mandernach, Carl S. Nelson, Jonathan R. Paulo, and Grover Saunders. 2012. "Usability Test Results for a Discovery Tool in Tabs and Tabulations 41 an Academic Library." Information Technology and Libraries 31 (1):83-112. http://dx.doi.org/10.6017/ital.v31i1.1855.

Ford, Lyle. 2010. "Better Than Google Scholar?: Results of Usability Testing with UM Students Using the Summon Discovery Layer." Paper presented at Internet Librarian, Monterey, California, October 25.

Howard, David, and Constance Wiebrands. 2011. “Culture Shock: Librarians' Response to Web Scale Search." Paper presented at Australian Library and Information Association, Sydney Australia, February. Accessed December 12, 2013. http://ro.ecu.edu.au/ecuworks/6206/.

Jansen, Bernard J. 2006. "Search Log Analysis: What It is, What's been Done, How to Do It." Library \& Information Research 28 (3):407-32. http://dx.doi.org/10.1016/j.lisr.2006.06.005

Liu, Suqing, Sansan Liao, and Jing Guo. 2009. "Surviving in the Digital Age by Utilizing Libraries' Distinct Advantages." Electronic Library 27 (2):298-307. http://dx.doi.org/10.1108/02640470910947647.

Lown, Cory, Tito Sierra, and Josh Boyer. 2013. "How Users Search the Library from a Single Search Box." College and Research Libraries 74 (3):227-41. http://dx.doi.org/10.5860/crl-321.

Meadow, Kelly, and James Meadow. 2012. "Search Query Quality and Web-Scale Discovery: A Qualitative and Quantitative Analysis." College \& Undergraduate Libraries 19 (2-4):163-75. http://dx.doi.org/10.1080/10691316.2012.693434.

Park, Minsoo, and Tae-Seok Lee. 2013. "Understanding Science and Technology Information Users through Transaction Log Analysis." Library Hi Tech 31 (1):123-40. http://dx.doi.org/10.1108/07378831311303976.

Sadeh, Tamer. 2008. "User Experience in the Library: A Case Study." New Library World 109 (1/2):7-24. http://dx.doi.org/10.1108/03074800810845976.

Teague-Rector, Susan, Angela Ballard, and Susan K. Pauley. 2011. "The North Carolina State University Libraries Search Experience: Usability Testing Tabbed Search Interfaces for Academic Libraries." Journal of Web Librarianship 5 (2):80-95. http://dx.doi.org/10.1080/19322909.2011.568822. 
Teague-Rector, Susan, and James Ghaphery. 2008. "Designing Search: Effective Search Interfaces from Academic Library Web Sites." Journal of Web Librarianship 2 (4):479-92.

http://dx.doi.org/10.1080/19322900802473944.

Williams, Sarah C., and Anita K. Foster. 2011. "Promise Fulfilled? An EBSCO Discovery Service Usability Study." Journal of Web Librarianship 5 (3):179-98. http://dx.doi.org/10.1080/19322909.2011.597590 